\title{
Pensando a Homoparentalidade: Um Estudo Qualitativo com Jovens Adultos Portugueses sem Filhos
}

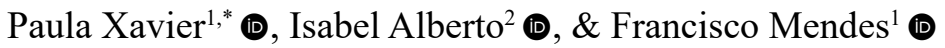 \\ ${ }^{1}$ Instituto Politécnico de Viseu, Viseu, Portugal \\ ${ }^{2}$ Universidade de Coimbra, Coimbra, Portugal
}

\begin{abstract}
RESUMO - O momento atual caracteriza-se por importantes mudanças sociais e legais, com potenciais repercussões na vida de pessoas lésbicas e gays. O presente estudo teve como objetivo identificar perceções de jovens adultos portugueses sem filhos relativamente ao eventual projeto de parentalidade. Foram realizadas entrevistas a sete pessoas que se autoidentificaram como lésbicas, gays e bissexuais e que se voluntariaram para participar no estudo. As transcrições das entrevistas foram submetidas a Análise Interpretativa Fenomenológica. Os temas emergentes revelaram que o desejo e a intenção de ter filhos se associavam à ponderação de desafios ligados ao heterossexismo, mas também à reflexão sobre condições e recursos a mobilizar para o enfrentar. São apresentadas implicações com vista à otimização das experiências individuais a este nível.
\end{abstract}

PALAVRAS-CHAVE: jovens adultos, lésbicas e gays, desejo de ter filhos, intenção de ter filhos, entrevistas

\section{Considering Same-sex Parenting:A Qualitative Study with Portuguese Childless Young Adults}

\begin{abstract}
The present period is characterized by important social and legal changes with potential repercussions in the lives of lesbian and gay people. This study aimed to identify perceptions of Portuguese childless young adults regarding the possible parenthood project. Interviews were conducted with seven people who self-identified as lesbian, gay and bisexual and who volunteered to participate in the study. Interview transcripts were subjected to Interpretative Phenomenological Analysis. Emerging themes revealed that desire and intention to have children arose associated with the consideration of challenges related to heterosexism, but also associated with reflection on the conditions and resources to be mobilized to tackle it. Implications for the optimization of individual experience at this level are presented.
\end{abstract}

KEYWORDS: young adults, lesbians and gay men, parental desires, parental intentions, interviews

A crescente diversidade familiar, o avanço nas técnicas de procriação medicamente assistida (PMA) e as conquistas ao nível dos direitos das minorias sexuais conduziram a importantes transformações nas oportunidades e restrições que as estruturas sociais colocam às famílias homoparentais (Gato et al., 2017; Goldberg, 2010), apesar dos desafios resultantes do heterossexismo que ainda prevalecem (Herek, 2009). Especificamente, as alterações legais mais progressistas configuram novas oportunidades para lésbicas e gays constituírem família, distintas das situações de homoparentalidade que têm ocorrido no contexto de uma relação heterossexual prévia ao coming out, mais frequentes num passado recente. Enquanto processo que integra o reconhecimento e a construção do sentido de si como lésbica, gay ou bissexual e o reconhecimento perante os outros em diferentes contextos como a família, a escola, o trabalho, ao longo do ciclo vital, o coming out pode ser influenciado por fatores contextuais tais como as atitudes do meio circundante e a idade e coorte (American Psychological Association [APA], 2012).

Em Portugal, essas alterações legais tiveram um forte impulso com a aprovação do casamento entre pessoas do mesmo sexo, em 2010 (Lei n. 9/2010, de 31/05), ainda que se mantivesse a impossibilidade de adoção em casal ( art. $^{\circ}$ 3..$^{\circ}$ da Lei n. 9/2010, de 31/05), e o recurso às técnicas de PMA se encontrasse limitado às situações de infertilidade

*E-mail: paulaxavier@esev.ipv.pt

- Submetido: 06/04/2018; Revisado: 27/09/2018; Aceito: 09/10/2018. 
(art. ${ }^{\circ}$ 4. $^{\circ}$ da Lei n. 32/2006, de 26/07). Esta situação veio a modificar-se em 2016, com a publicação da Lei n. 2/2016, de 29/02, que eliminou as limitações e interdições no acesso à adoção, ao apadrinhamento civil e às demais relações jurídicas familiares por casais do mesmo sexo; e da Lei n. 17/2016, de 20/06, que permitiu o acesso à inseminação artificial (IA) a todas as mulheres, independentemente do estado civil e orientação sexual $\left(\right.$ art. $\left.^{\circ} 6^{\circ}{ }^{\circ}\right)$.

Esse progresso no plano jurídico português coexiste com um clima social de reserva em relação a estas famílias. Num estudo com uma amostra da população portuguesa $(N$ =993), Costa et al. (2013) verificaram que, apesar de uma atitude maioritariamente favorável à homoparentalidade, os participantes mostraram-se mais apoiantes da parentalidade por casais heterossexuais, antecipando maiores dificuldades emocionais e sociais nas crianças adotadas por casais do mesmo sexo. Também Ramos et al. (2016) analisaram as atitudes em relação às famílias homoparentais (entre outras) numa amostra representativa da população portuguesa $(N$ $=1001)$. E, relativamente à questão sobre duas mulheres poderem criar uma criança de forma tão adequada quanto um casal heterossexual, $70.5 \%$ das mulheres e $55.2 \%$ dos homens, com idades entre os 18 e os 29 anos, concordaram. Esta mesma questão, tendo por referência os casais do sexo masculino, suscitou posicionamentos menos favoráveis, sobretudo por parte dos participantes homens e mais velhos.

As mudanças legais e sociais atuais poderão criar um efeito de coorte de influência nas aspirações parentais das gerações mais novas de lésbicas e gays, no sentido de fazerem o coming out mais cedo e incluírem a parentalidade nos seus projetos de vida (Gato et al., 2017; Goldberg, 2010; Herek, 2009; Rabun \& Oswald, 2009; Stacey, 2006). Este contexto propicia o foco da investigação no projeto de parentalidade, consubstanciado no desejo (querer) e na intenção de ter filhos (tomada de decisão e plano) (Miller, 1994, 2011).

Bos et al. (2003) compararam casais de lésbicas que tiveram filhos por meio de IA e casais heterossexuais sem história de problemas de fertilidade, e verificaram que os primeiros referiram ter refletido mais sobre os motivos da parentalidade e apresentavam um desejo mais forte para ter filhos do que os casais heterossexuais. Riskind e Patterson (2010), num estudo com uma amostra de heterossexuais, gays e lésbicas, com idades entre os 15 e os 44 anos e sem filhos, verificaram que estes últimos atribuíam o mesmo valor à parentalidade que os heterossexuais. Todavia, comparativamente aos pares heterossexuais, os gays e lésbicas manifestaram de forma menos marcada o desejo de ter filhos. Noutro estudo com uma amostra de lésbicas, gays e heterossexuais sem filhos, Baiocco e Laghi (2013) também constataram que os primeiros reportaram menos o desejo e a intenção de ter filhos, comparativamente aos pares heterossexuais.

Em Portugal, onde a investigação sobre a homoparentalidade em geral, e particularmente sobre a parentalidade enquanto projeto se encontra em fase de afirmação, Costa e Bidell (2017) realizaram um estudo com uma amostra de lésbicas, gays e bissexuais $(N=568)$, com idades entre os 18 e os 76 anos $(M=31, D P=10)$, com o objetivo de analisar o desejo e a intenção de terem filhos. Uma minoria $(n=38)$ referiu ter filhos. Entre os participantes sem filhos $(n=530)$, em média, 12 anos mais novos, a maioria manifestou o desejo $(66 \%)$ de ter filhos e a intenção (56\%) de o fazer no futuro. Ser mais novo, ter pouco envolvimento religioso e integrar eventos da comunidade LGBT (lésbicas, gays, bissexuais, trans) mostraram ser preditores significativos da intenção de ter filhos. Os participantes mais novos manifestaram uma intenção parental significativamente mais forte do que os mais velhos.

Em estudos qualitativos realizados com gays sem filhos (Rabun \& Oswald, 2009), gays com filhos (Gianino, 2008), gays com e sem filhos (Berkowitz, 2011; Berkowitz \& Marsiglio, 2007; Stacey, 2006) e lésbicas com filhos (Chabot \& Ames, 2004; Touroni \& Coyle, 2003) o desejo de ser pai/ mãe surgiu de forma destacada. Porém, esse desejo foi, em parte, reportado de forma retrospetiva, especificamente nos estudos que incluíram participantes com filhos, tal como aconteceu na pesquisa de Bos et al. (2003). Mas o desejo de ter filhos nem sempre foi evidenciado. Num estudo em que foram entrevistados gays, Stacey (2006, p. 33) referiu-se ao "passion-for-parenthood continuum" para representar a diversidade de atitudes face à parentalidade. $\mathrm{O}$ "passionfor-parenthood continuum" incluía desde os pais para quem ter filhos era um projeto de vida essencial, até àqueles que manifestavam rejeição da parentalidade, encontrando-se numa zona intermédia os "situational parents" (que foram pais, por exemplo, graças a um companheiro motivado). Em Portugal, Aboim et al. (2012) entrevistaram lésbicas $(n=10)$ e gays $(n=20)$, com e sem filhos, e também encontraram narrativas reveladoras de uma diversidade de projetos relativamente à parentalidade, desde a decisão de não a incluir no seu projeto de vida, até ao desejo manifesto de ter filhos, passando pelos que estavam indecisos.

Segundo Miller (1994, 2011), a intenção de avançar para o projeto de parentalidade, para além de ser determinada pelo desejo de ter filhos, é influenciada por fatores como o desejo do/a companheiro/a de ser pai/mãe e o apoio da família e amigos. Por seu turno, a implementação das intenções em comportamentos é influenciada pelos acontecimentos de vida, apoio social e presença de obstáculos à concretização. Deste modo, a investigação em torno do projeto/intenção de parentalidade de lésbicas e gays deve também focar-se nos fatores que poderão influenciar as suas tomadas de decisão. Com base na revisão da literatura, Gato et al. (2017), Goldberg (2010) e Mezey (2013) sistematizaram um conjunto de fatores que englobam as dimensões individual, relacional e contextual.

Ao nível individual, para além do desejo, ou não, de ter filhos, é determinante a influência da homofobia internalizada (Aboim et. al, 2012; Berkowitz \& Marsiglio, 
2007; Brown et al., 2009; Chabot \& Ames, 2004; Gianino, 2008). As mensagens heterossexistas e as vivências associadas à ostracização, discriminação e preconceito podem resultar na internalização e direcionamento contra o/a próprio/a das atitudes negativas da sociedade em relação à homossexualidade (Herek, 2009). Nesse sentido, pode haver lugar também ao questionamento da competência parental e receio de consequências negativas para as crianças, apesar da evidência científica de que a orientação sexual não constitui critério para a definição da qualidade parental (cf. APA, 2005; Goldberg et al., 2014; Ordem dos Psicólogos Portugueses, 2013). No entanto, a capacidade e a necessidade de fazer o coming out (Meyer, 2003) pode promover a superação da autoavaliação negativa e conduzir à autoaceitação facilitadora da concretização do projeto de ter filhos.

A homofobia internalizada também tem vindo a ser analisada sob uma perspetiva relacional. Frost et al. (2017) entrevistaram 120 casais, 60 femininos e 60 masculinos, com o objetivo de analisar a forma como a relação com uma pessoa do mesmo sexo pode implicar a exposição a fatores de stress associados à condição de minoria para além dos que são considerados no nível individual. Verificaram que a existência de discrepâncias, na díade, em questões relacionadas com a internalização do estigma e abertura com o exterior se traduziam em stress ao nível do casal, por exemplo, ao limitarem a possibilidade de ambos os elementos tornarem a relação visível. Num estudo realizado com gays em situação de pré-adoção Goldberg et al. (2012) concluíram que o coming out mais tardio de um dos elementos do casal poderia protelar a decisão de ter filhos. Ainda na dimensão relacional, um/a companheiro/a que não deseje ter filhos poderá dificultar a concretização do projeto de parentalidade (Goldberg, 2010), enquanto um/a companheiro/a que pretenda ter filhos pode consolidar o desejo ou facilitar a passagem para a intenção de os ter (Berkowitz \& Marsiglio, 2007; Chabot \& Ames, 2004; Goldberg et al., 2012; Stacey, 2006). Em alguns casos, o desacordo pode levar à dissolução da relação e procura de alguém que também queira ter filhos (Berkowitz, 2011; Goldberg et al., 2012; Touroni \& Coyle, 2002) ou, por outro lado, ao desenvolvimento da motivação no outro elemento do casal após um processo de negociação (Berkowitz \& Marsiglio, 2007).

A terceira dimensão a considerar é o apoio proporcionado pela rede social, designadamente a família e os amigos, que pode ser percebido como facilitador ou como obstáculo (Baiocco \& Laghi, 2013; Berkowitz \& Marsiglio, 2007; Brown et al., 2009; Chabot \& Ames, 2004; Rabun \& Oswald, 2009; Touroni \& Coyle, 2002). No estudo de Costa e Bidell (2017) não se verificou um efeito significativo do apoio dos amigos na intenção parental. Além disso, a literatura mostra que a disponibilidade e o apoio da comunidade ou de outros pais/mães gays e lésbicas poderá constituir-se como um fator protetor face ao heterossexismo, permitindo igualmente $\mathrm{o}$ acesso a modelos de família/parentalidade e a informação sobre formas de acesso à parentalidade (Berkowitz \& Marsiglio, 2007; Chabot \& Ames, 2004; Costa \& Bidell, 2017; Gianino, 2008; Goldberg, 2010; Goldberg et al., 2012; Stacey, 2006). Reforçando esta ideia, uma das barreiras identificadas por alguns participantes num estudo que Brown et al. (2009) realizaram com lésbicas e gays com filhos foi a falta de apoio da comunidade gay quando decidiram adotar.

Quanto ao contexto social mais ampliado, a condição laboral assume um papel preponderante associado à estabilidade económica e às garantias sociais que proporciona ou não, atendendo aos custos que a educação de uma criança $\mathrm{e} o$ acesso à parentalidade podem comportar (Aboim et al., 2012; Berkowitz \& Marsiglio, 2007; Chabot \& Ames, 2004; Goldberg et al., 2012; Mezey como citado em Mezey, 2013; Rabun \& Oswald, 2009). Além disso, o contexto laboral poderá ser mais uma área de vida onde terão que ser geridos os desafios do heterossexismo (Gato et al., 2017). Devem ainda ser consideradas as oportunidades ou obstáculos ao nível legal, médico e social que, para além de determinarem a informação que se encontra ou não disponível, são preponderantes no acesso à parentalidade, podendo interferir nas intenções parentais (Aboim et al., 2012; Baiocco \& Laghi, 2013; Berkowitz \& Marsiglio, 2007; Bos et al., 2003; Brown et al., 2009; Chabot \& Ames, 2004; Gianino, 2008; Goldberg, 2010; Rabun \& Oswald, 2009; Touroni \& Coyle, 2002). Por exemplo, um dos obstáculos pode advir das atitudes dos profissionais com quem lésbicas e gays terão que contactar nos serviços de adoção e saúde (e.g., Berkowitz \& Marsiglio, 2007; Brown et al., 2009; Gianino, 2008; Xavier et al., 2017).

De acordo com várias pesquisas, conhecer/ter amiga/ os lésbicas e gays com filhos (e.g., Berkowitz \& Marsiglio, 2007; Chabot \& Ames, 2004; Goldberg et al., 2012), contactar com os filhos dos outros e/ou conviver com crianças (Berkowitz \& Marsiglio, 2007), experimentar uma noção crescente do desejo de ter filhos e conhecer alguém especialmente motivado (Berkowitz \& Marsiglio, 2007; Chabot \& Ames, 2004; Stacey, 2006), poderão constituir um ponto de virada na vida de lésbicas e gays em matéria de parentalidade (Goldberg, 2010).

As perspetivas ecológica e sistémica sustentam que a (homo)parentalidade é determinada por fatores individuais (características dos pais/mães e crianças) e contextuais, desde os mais próximos (relações e rede de apoio) aos mais afastados (condições oferecidas pela sociedade) (Alarcão, 2006; Belsky, 1984, 2008; Bronfenbrenner, 1977; Goldberg, 2010). Nos estudos anteriormente revistos ressalta que esses fatores também influenciam a tomada de decisão de ter filhos (Gato et al., 2017; Goldberg, 2010; Mezey, 2013; Miller, 1994, 2011). Outra dimensão a considerar é o tempo (Elder, 1998; Goldberg, 2010). Para Elder (1998), as trajetórias de vida individuais inserem-se e são enquadradas pelo tempo histórico e lugares onde ocorrem, que the conferem um significado e uma forma distintos. Os 
indivíduos constroem a sua trajetória de vida por meio de escolhas e ações realizadas em função das oportunidades e restrições das estruturas sociais. Concretamente no que diz respeito aos projetos de parentalidade de lésbicas e gays, essas oportunidades e restrições incorporam as influências do heterossexismo ao nível das instituições e sistemas ideológicos (e.g., disposições jurídicas mais ou menos restritivas), e da discriminação antecipada/ experimentada nas interações entre maioria e minoria (Brown et al., 2009; Goldberg, 2010; Herek, 2009), obrigando à mobilização de estratégias de coping (Herek, 2009; Meyer, 2003).

Reconhecendo a importância de ampliar o investimento da investigação neste domínio específico da homoparentalidade (Gato et al., 2017; Mezey, 2013), nomeadamente em Portugal, e considerando os desafios associados ao estatuto de minoria mas também as oportunidades que se têm vindo a consolidar, sobretudo em termos legais, importa compreender as perspetivas de pessoas lésbicas e gays que eventualmente ponderam incluir a parentalidade no seu projeto de vida, em particular os jovens adultos. Esta fase do desenvolvimento envolve tarefas como a tomada de decisão sobre estilos de vida pessoais e relacionamentos íntimos (Papalia et al., 2006), e muitos são aqueles que se envolvem em uniões estáveis e têm filhos, ainda que também se tenha vindo a assistir ao adiamento da parentalidade por diversos motivos, entre os quais se destacam as condições económicas (Mills et al., 2011).

Assim, o presente estudo foi orientado pela seguinte questão: o que pensam as lésbicas e gays portugueses em relação à possibilidade de terem filhos? O principal objetivo foi identificar as perceções de jovens adultos portugueses relativamente ao eventual projeto de homoparentalidade. Tratase de uma análise prospetiva (i.e., anterior à parentalidade), complementar à abordagem retrospetiva presente noutros estudos qualitativos (Aboim et al., 2012; Berkowitz, 2011; Berkowitz \& Marsiglio, 2007; Chabot \& Ames, 2004; Gianino, 2008; Stacey, 2006; Touroni \& Coyle, 2002), e focada nas construções de sentido associadas ao desejo e intenção de ter filhos (cf. Costa \& Bidell, 2017) no contexto português. Foi enfatizada a compreensão da singularidade das vivências destes jovens adultos em detrimento de uma abordagem comparativa com as dos pares heterossexuais (cf. Gato, 2016). Espera-se que os resultados possam contribuir para o aprofundamento do conhecimento desta temática, constituindo de igual modo uma oportunidade para a reflexão de lésbicas e gays relativamente ao projeto de parentalidade (e sua concretização), mas também dos profissionais envolvidos na temática do acesso e regulação da parentalidade.

\section{MÉTODO}

O presente estudo enquadra-se no paradigma construtivista (Lincoln, Lynham, \& Guba, 2011) e foi desenvolvido de acordo com a Análise Fenomenológica Interpretativa, uma abordagem ideográfica que preconiza a exploração em detalhe da forma como os participantes constroem um sentido para o seu mundo pessoal e social (Smith \& Osborn, 2008). Adequa-se, assim, à análise das experiências pessoais em torno da ponderação do eventual projeto de homoparentalidade. Esta abordagem envolve ainda uma situação de dupla hermenêutica (Smith \& Osborn, 2008), em que é assumido que os participantes estão a construir um sentido para o seu mundo e o investigador a elaborar um sentido para essa construção.

\section{Participantes e Contexto}

Participaram sete pessoas sem filhos, quatro do sexo masculino e três do sexo feminino, que se autoidentificaram como lésbicas $(n=2)$, gays $(n=4)$ e bissexuais $(n=1)$. $\mathrm{O}$ intervalo de idades era 23-33 anos $(M=27.3 ; D P=3.49)$. Todos os participantes eram portugueses. Seis residiam em duas das maiores cidades portuguesas (mais de 100 mil habitantes) ou na respetiva área metropolitana. Uma participante residia num município com menor densidade populacional (menos de 11 mil habitantes). Todos tinham habilitações académicas de nível superior. No momento da entrevista apenas um não trabalhava. Cinco participantes estavam numa relação com uma pessoa do mesmo sexo, sendo que três deles viviam com a/o companheira/o. Duas participantes mantinham uma relação afetiva entre si.

$\mathrm{Na}$ Tabela 1, foram sistematizadas as características sociodemográficas dos participantes. Atendendo aos fatores que, a nível individual, relacional e contextual, poderão influenciar as tomadas de decisão relativas ao projeto de parentalidade (Miller, 1994, 2011), as características sociodemográficas, assim como o período de debate político e social que antecedeu a regulamentação do acesso à adoção por casais do mesmo sexo e às técnicas de PMA por qualquer mulher, durante o qual foram realizadas as entrevistas, constituem o contexto deste estudo.

\section{Técnica e Procedimentos de Coleta dos Dados}

Os dados foram coletados por meio de entrevista semiestruturada. Foi utilizado um guia construído para este estudo com base na literatura teórica sobre família e parentalidade, designadamente as perspetivas ecológica e sistémica. Para além dos dados de caracterização sociodemográfica, foram colocadas questões que visavam a exploração das perceções e construções de sentido relativamente a dois tópicos: (a) a parentalidade de um modo geral (competências e características pessoais mais relevantes; fatores contextuais; perceção sobre a 
Tabela 1

Características Sociodemográficas dos Participantes

\begin{tabular}{|c|c|c|c|c|c|c|}
\hline $\begin{array}{c}\text { Nome } \\
\text { (fictício) }\end{array}$ & Idade & Sexo & Autoidentificação & Estado civil $^{\mathrm{a}}$ & $\begin{array}{l}\text { Habilitações } \\
\text { académicas }\end{array}$ & $\begin{array}{c}\text { Situação } \\
\text { profissional }\end{array}$ \\
\hline Gil & 33 & M & Gay & Vive com o companheiro & Licenciatura & Empregado \\
\hline Nuno & 27 & M & Gay & Solteiro & Mestrado & Empregado \\
\hline Luís & 31 & M & Gay & Solteiro & Mestrado & Bolsista de pesquisa \\
\hline João & 26 & M & Gay & Numa relação & Licenciatura & Empregado \\
\hline Ana & 26 & $\mathrm{~F}$ & Lésbica & Vive com a companheira & Mestrado & Empregada \\
\hline Diana & 23 & $\mathrm{~F}$ & Lésbica & Numa relação & Licenciatura & $\begin{array}{l}\text { À procura do } 1 .^{\circ} \\
\text { emprego }\end{array}$ \\
\hline Lúcia & 25 & $\mathrm{~F}$ & Bissexual & Vive com a companheira & Mestrado & Empregada \\
\hline
\end{tabular}

Note. $\mathrm{M}=$ Masculino; $\mathrm{F}=$ Feminino.

${ }^{\mathrm{a}}$ Inclui informação sobre os participantes solteiros, os que namoravam e os que moravam com o/a companheiro/a.

influência da orientação sexual; principais desafios que pais/mães têm que gerir na atualidade e como os poderão enfrentar); (b) as expectativas em torno do eventual projeto de parentalidade. Tal como é preconizado pela Análise Fenomenológica Interpretativa, a opção por entrevista semiestruturada permitiu que fosse estabelecido um diálogo entre investigadora e participantes onde, para além da abordagem dos tópicos norteadores, emergisse a exploração de temáticas introduzidas por estes últimos (Smith \& Osborn, 2008).

Foram estabelecidos contactos com associações representativas dos direitos LGBT a quem foi apresentado o projeto de investigação e que o divulgaram. Dois participantes contactaram a primeira autora por email e voluntariaram-se para participar na entrevista. Quanto aos restantes, dois foram contactados por intermédio da rede de contactos dos autores e três mediante indicações dos participantes anteriores, por meio do método snowball (Yin, 2011). Como é reconhecido na literatura da área (e.g., Goldberg, 2010), apesar da evolução já ocorrida na sociedade, devem ser ponderadas as influências do heterossexismo na disponibilidade para a colaboração em projetos de investigação. Não obstante, também deve ser ressalvado que existem trabalhos publicados que recorreram à Análise Interpretativa Fenomenológica cujo número de participantes varia entre "um, quatro, nove, quinze e mais" (Smith \& Osborn, 2008, p. 56) e que a ênfase desta abordagem está na análise em profundidade das perceções e significados que os indivíduos atribuem ao seu mundo pessoal e social.

Previamente à realização da entrevista, os participantes foram contactados para uma nova apresentação do estudo, confirmação da participação e agendamento da data e local. Em conformidade com os princípios éticos estabelecidos pela Ordem dos Psicólogos Portugueses, pela American Psychological Association e pela Declaração de Helsínquia para o domínio da investigação, no início da entrevista foram assinados os consentimentos informados de participação e as autorizações para a gravação áudio, tendo sido garantidos a confidencialidade e o anonimato na apresentação dos resultados. As entrevistas foram conduzidas pela primeira autora, psicóloga, e realizadas em local indicado pelos participantes, a maioria $(n=6)$ no seu domicílio. Tiveram uma duração máxima de 1 hora e 56 minutos e mínima de 48 minutos. A duração média foi de 1 hora e 20 minutos. As entrevistas gravadas foram, posteriormente, transcritas integralmente.

\section{Procedimentos de Análise dos Dados}

As narrativas foram analisadas de acordo com os procedimentos da Análise Fenomenológica Interpretativa (IPA; Smith \& Osborn, 2008). Esta abordagem reconhece um papel ativo ao investigador no acesso ao mundo pessoal dos participantes, implicando a atenção a ideias preconcebidas no sentido de facilitar a expressão dos fenómenos e permanecer aberto a novas construções de sentido (bracketing; Finlay, 2014). Face a isto, considerou-se relevante realizar a revisão aprofundada da literatura científica da área do estudo só após a análise das entrevistas, no sentido de não determinar os significados encontrados aos reportados noutros estudos.

De acordo com Smith e Osborn (2008), após nova escuta da entrevista, foram efetuadas leituras repetidas da transcrição do primeiro caso procedendo-se ao registro de notas respeitantes ao conteúdo e a primeiras interpretações. Essas anotações foram transformadas em temas emergentes, com um nível maior de abstração, que foram depois agregados de acordo com semelhanças conceptuais, resultando numa hierarquização de temas principais e subtemas. A comparação permanente com a narrativa do participante foi transversal a estes procedimentos, os quais foram repetidos para cada caso. Depois, num processo iterativo, foram reanalisados e sistematizados todos os temas e subtemas, de todos os casos, procedendo-se a novas agregações quando se verificavam semelhanças de sentido. Nesta fase recorreu-se ao software NVivo (Version 8; QSR International, 2008). Esta última etapa permitiu a identificação de padrões de significados recorrentes (Smith, 2011), nomeadamente os temas e subtemas 
referidos por pelo menos quatro dos participantes, os quais constituíram o foco desta análise. A fim de permitir a verificação das interpretações (Finlay, 2014; Smith \& Osborn, 2008; Touroni \& Coyle, 2002), a sua apresentação fez-se acompanhar de excertos das narrativas dos participantes. Procurou-se, assim, ir ao encontro de uma análise sensível aos padrões mais recorrentes e, ao mesmo tempo, ideográfica. Nesses excertos, por forma a manter o anonimato, recorreu-se a nomes fictícios. As reticências assinalam as partes cortadas e os parêntesis retos enquadram as clarificações.

A análise foi realizada pela primeira autora, tendo os coautores efetuado a revisão dos temas finais, confrontandoos com as narrativas dos participantes (Yardley, 2008).

\section{RESULTADOS}

Seis dos sete participantes manifestaram de forma clara o desejo de ter filhos. $\mathrm{Na}$ Tabela 2, foram sistematizados os temas e subtemas relacionados com as construções de sentido em torno da ponderação de ter filhos, organizados em três tópicos principais, designadamente as motivações sobre a parentalidade, as perceções acerca da influência da orientação sexual na parentalidade e as perceções em torno das condições e desafios que poderão associar-se ao projeto de se tornar pai/mãe.

\section{Motivações sobre a Parentalidade}

O desejo de ter filhos surgiu associado a motivações positivas (Miller, 1994, 2011) como o facto de gostarem de crianças $(n=4)$ - “[quanto] à parte de me imaginar como pai, tenho gosto de estar com as crianças [e.g., os sobrinhos], por mais que elas possam chorar eternidades ou fazer as birras" (João) - e a vontade de contribuir para o desenvolvimento de uma pessoa $(n=6)$ - "é muito importante a educação, o tempo que nós estamos com eles, a qualidade, porque eles aprendem com isso" (Gil).

Ao nível das intenções, os seis participantes consideraram que ainda não seria o momento certo para avançar, ponderando a presença de motivações negativas (Miller, 1994, 2011), nomeadamente as dúvidas sobre se já estão preparados para ter filhos $(n=4)$ - "eu lá por ter 23 anos, tenho muito que crescer, tenho muito que amadurecer para tomar conta de alguém" (Diana) - e/ou o facto de a parentalidade implicar ficar sem tempo para outros projetos pessoais $(n=4)$ - "nós temos planos pessoais ainda muito importantes à frente... ou pelo menos tão importantes quanto a parentalidade. E ainda não decidimos desistir de nenhum deles por causa disso" (Luís). Ainda neste contexto, cinco participantes manifestaram apreensões relativamente às responsabilidades associadas à parentalidade:

Tabela 2

Temas e Subtemas que Emergiram da Análise das Entrevistas aos Participantes (Mencionados por pelo menos 4 dos 7 Participantes)

\begin{tabular}{|c|c|}
\hline Temas & Subtemas \\
\hline \multirow[t]{2}{*}{ Motivações sobre a parentalidade } & Motivações positivas \\
\hline & Motivações negativas \\
\hline \multirow{3}{*}{$\begin{array}{l}\text { Influência da orientação sexual dos } \\
\text { pais/mães na parentalidade }\end{array}$} & Não determina a competência parental \\
\hline & Não determina de forma direta o desenvolvimento dos filhos \\
\hline & Consequências das atitudes sociais \\
\hline \multirow{5}{*}{$\begin{array}{l}\text { Condições e desafios da parentalidade } \\
\text { ao nível Pessoal }\end{array}$} & Estabilidade pessoal/maturidade \\
\hline & Estabilidade económica \\
\hline & Coming out \\
\hline & Investimento pessoal aumentado \\
\hline & Responsabilidades aumentadas \\
\hline \multirow{5}{*}{$\begin{array}{l}\text { Condições e desafios da parentalidade } \\
\text { ao nível das Relações Próximas }\end{array}$} & Estabilidade da relação com o/a companheiro/a \\
\hline & Desejo de partilhar as responsabilidades parentais \\
\hline & Qualidade do apoio da rede informal \\
\hline & Insegurança relativamente ao apoio para o projeto de homoparentalidade \\
\hline & Negociação dentro do casal \\
\hline \multirow{5}{*}{$\begin{array}{l}\text { Condições e desafios da parentalidade } \\
\text { ao nível do Contexto Social }\end{array}$} & Conciliação entre trabalho e vida familiar \\
\hline & (In)suficiências do apoio instrumental da rede formal às famílias (geral) \\
\hline & Atitudes sociais em relação à homossexualidade \\
\hline & Insuficiências do apoio da sociedade às famílias homoparentais \\
\hline & Modelos (in)disponíveis para a homoparentalidade \\
\hline
\end{tabular}


É preciso passar por muitas coisas más [desagradáveis] quando se tem filhos, nomeadamente não dormir durante não sei quantos meses, desistir de sair à noite, desistir de estar com os amigos, desistir de fazer montes de coisas... Imaginar-me a não conseguir dormir porque o filho está a chorar e a não conseguir descansar... é complicado, pronto. (Ana)

A participante que referiu não se identificar com o projeto de parentalidade, dissociando a sua opção da sua orientação sexual, também se referiu a essas apreensões:

É uma coisa perfeitamente independente da minha sexualidade... pode ser que mude, não sei... A questão é que eu não me identifico com esse papel, ou seja, não me vejo a ser essa pessoa... que está lá para dar comida, para acordar quatro vezes a meio da noite, para ir buscar à escola, tirar da escola, aturar birras... Independentemente dos ótimos momentos... não me imagino a fazer todos os sacrificios. (Lúcia)

\section{Influência da Orientação Sexual dos Pais/ Mães na Parentalidade}

Este tema diz respeito a um conjunto de perceções partilhadas por todos os participantes como relevantes na ponderação do projeto de parentalidade, começando por estabelecer que a orientação sexual - e o género - não determina a competência parental:

Acho que não tem nenhuma influência [a orientação sexual dos pais]... Como estes casais [do mesmo sexo] são vistos de forma diferente na lei, isso depois vai ter alguma repercussão. Mas isso já é um passo um bocadinho à frente... Na relação da família não vejo que tenha influência... Não acho que no cômputo geral isso... determine que aquelas pessoas vão ser melhores pais ou piores pais... Em termos de papéis, eu também não acho que haja nenhum papel naturalmente masculino ou feminino num casal, seja ele qual for. (Luís)

Os participantes também referiram que a orientação sexual dos pais/mães não determina de forma direta o desenvolvimento dos filhos sustentando-se inclusive na investigação científica: "Por aquilo que a ciência nos tem mostrado, e que os estudos feitos com famílias nos têm mostrado... não existe... praticamente diferença nenhuma [nos filhos] em termos de orientação sexual, em termos de escolaridade" (Ana). Não obstante, o conhecimento que têm da realidade circundante levou-os a equacionar as consequências das atitudes sociais no desenvolvimento das crianças, que também ponderaram quando refletiram sobre as condições e os desafios associados à tomada de decisão e ao futuro papel parental, quer ao nível individual, quer relacional e social, como será desenvolvido nos temas seguintes. A ponderação desse impacto é evidente no excerto que se segue:
Imaginemos, por exemplo, um casal de dois homens e um casal de um homem e uma mulher, os dois com filhos de sete anos a entrar para a escola primária; enfim, direi que a probabilidade joga contra o filho do casal de dois homens, por exemplo, em termos de tudo aquilo que nós sabemos, dos gozos [piadas] nas escolas... Mas não creio que seja algo inultrapassável, mas que, se condiciona? Sim! (Nuno).

\section{Condições e Desafios da Parentalidade ao Nível Pessoal}

Este tema remete para as condições que, na perspetiva dos participantes, deverão ser acauteladas ao nível individual para a concretização do projeto de parentalidade. Alguns participantes $(n=5)$ sublinharam a estabilidade pessoal/ maturidade - "as pessoas têm que estar bem física, psicologicamente... equilibradas para poder aceitar mais alguém no seio familiar" (Diana). A totalidade dos sujeitos realçou a estabilidade económica - "tracei para mim próprio ali para os 35 anos começar a pensar na coisa [ter filhos] com mais seriedade para ter já... as finanças mais orientadas" (Nuno); "nós estamos num tal estado de incerteza que também tem muito a ver, acho eu, com o trabalho ser incerto... Também não nos dá essa estabilidade... para pensar a sério neste investimento [ter filhos]" (Luís).

Num sentido mais específico, nas narrativas de seis participantes emergiram questões relacionadas com o coming out. Como se pode depreender da experiência de uma das participantes, as vivências associadas ao coming out foram percebidas como fundamentais não apenas ao nível individual, em termos de autoaceitação, mas também na relação com os outros, concretamente com a companheira, por exemplo se houver uma discrepância a este nível na díade. Essa abertura foi perspetivada como uma tarefa em aberto e desafiadora na relação (também da família) com os outros e com a sociedade:

Já me assumo como lésbica há muito tempo, há cerca de 10 anos... Foi difícil ao princípio, mas depois foi sendo mais fácil e com cada vez mais abertura... Mas agora estou [numa relação e] é complicado porque envolve outra pessoa que não se quer expor... Acho que a única forma de mudar a sociedade e a forma como as pessoas pensam, apesar de ser à nossa custa e à custa dos nossos filhos, é pormo-nos no meio dela. E é integrarmo-nos no meio dela, e pôr os nossos filhos nas escolas normais, e nós próprios assumirmo-nos no local do trabalho... Até porque nós só vamos mudar as mentalidades das pessoas quando lhes mostrarmos as realidades diferentes. (Ana)

Ainda ao nível das condições e desafios individuais, todos os participantes destacaram a necessidade de um investimento pessoal aumentado na hora de pensar o projeto de parentalidade, implicando a exploração de formas de acesso mediante uma procura ativa de informação e tendo presente a salvaguarda da criança: 
O primeiro desafio seria como é que nós conseguiríamos ter uma criança. Claro, não é fácil, [como é para] um casal heterossexual... Já li algumas coisas... Lá está, eu acho que temos que estar informados, saber quais são as possibilidades... [refletindo sobre a possibilidade de recorrer a uma "barriga de aluguel"] Como é ilegal, como é que isso se processaria?... Eu seria pai na mesma, portanto, mas imagino que a criança será sempre dos dois e eu deixarei de ter, à partida, relação com aquela mulher. Havendo alguma coisa, ela poderá sempre questionar o poder parental, não é?... Lá está, eu posso gostar muito de ter uma criança, mas não vou assim, à toa, começar a pensar em outras questões porque, depois, não estou salvaguardado, não posso depois criar mais sofrimento àquela criança. (Gil)

Nesta sequência, numa projeção do eventual papel de pai/mãe, seis participantes anteciparam a necessidade de assumir responsabilidades aumentadas, no sentido de estarem preparados e de prepararem os filhos para lidar com as atitudes do meio e com o seu impacto. Como referiu uma das participantes:

Estamos a lidar com crianças, estamos a lidar com a sociedade... temos que ter a capacidade de apoiar muito... Temos que nos preparar para lidar com isso. E ajudar a criança a lidar com isso, para que aquilo não tenha um impacto negativo, como o medo de ir à escola ... porque está sempre a passar por, entre aspas, "meterem abaixo a criança". (Diana)

\section{Condições e Desafios da Parentalidade ao Nível das Relações Próximas}

Neste tema foram integradas as condições que os participantes consideraram ser primordiais no contexto das suas relações próximas para surgir a intenção de ter filhos. A importância da estabilidade da relação com o/a companheiro/a - "há a questão de que ainda não sei se a minha relação é sólida" (Diana) - foi identificada por cinco participantes, eventualmente associada ao desejo de partilharem as responsabilidades parentais $(n=4)$, assumindo que cada um dos elementos do casal dará o seu contributo - "quando se tem [um filho] com outra pessoa também há a esperança, não é?, de que algumas competências que faltem a um, o outro possa compensar... Eu ter um filho sozinho... está fora de questão" (Luís). A valorização do apoio que, enquanto pais/mães poderão ter por parte da rede informal, como condição para a intenção de ter filhos, foi unânime - "o facto de ter família próxima, ou amigos muito próximos que possam ficar com as crianças, caso eu não possa..., que possam auxiliar, acho que isso é importante" (Gil).

No que diz respeito às vivências especificamente associadas à orientação sexual, esse apoio da rede informal foi qualificado como um facilitador, como por exemplo, aquele que pode ser encontrado na comunidade gay:
Eu estive três anos a estudar fora... numa cidade, não quer dizer que esteja muito evoluída em questões de mentalidade mas [onde] há outras informações a correr..., a comunidade homossexual é maior do que aqui, certo?... [Lá] tive a oportunidade de estar com pessoas que até já se casaram e que também acabaram por, em conversa, falar... que tinham de ir não sei onde para concretizarem a inseminação. Foi importante e, também, mesmo em questões de como eu via certas coisas [relacionadas com a sua orientação sexual]. (Diana)

Porém, a rede social também foi percebida como um possível desafio:

eu conheço algumas pessoas para quem é mais fácil fazer este passo [revelação aos outros]... Mas, pensando na generalidade da população... estes pais ou mães vão ser alvo de críticas, vão ser alvo de piadas, vão ser alvo de mudanças de atitude por parte das pessoas que os rodeiam. (Ana)

Na sequência desta segunda perceção, quatro participantes referiram a insegurança relativamente ao apoio da sua família, e restante rede informal, para o projeto de (homo) parentalidade. Como referiram dois deles:

A primeira coisa que o meu pai me disse quando eu lhe disse que era homossexual foi 'mas assim eu não vou ter netos a sério'. E eu disse 'mas pai, eu posso ter filhos'. E ele disse 'não vai ser a mesma coisa'... E é preciso gerir isso. E eu acho que isso é completamente ultrapassável... mas acho que existe muito esta ideia de que não é a mesma coisa, de que não é o natural... É uma coisa dificil de gerir mas acho, sinceramente, que é ultrapassável, tal como é ultrapassável os pais aceitarem os filhos como homossexuais. (Ana)

Embora a família, colegas, amigos, etc., estejam muito confortáveis com a minha homossexualidade, não sinto que estejam muito confortáveis com a ideia de eu ser pai. Algumas pessoas estarão, mas outras nem tanto... Porque de repente há crianças... na história e já não se trata só de 'ele faz o que quer com a vida dele', não é? 'Ele já está a fazer o que quer com a vida dele e com a vida das crianças!' (Luís)

Ainda numa dimensão relacional, foi realçado o contributo do investimento a dois/duas, com a valorização, por parte de cinco participantes, da negociação dentro do casal enquanto tarefa a cumprir antes de avançar para o projeto de parentalidade atendendo às especificidades associadas à sua orientação sexual, como é evidenciado numa das narrativas:

Tem muito a ver, também, com o companheiro ou a companheira... Quem é que vai ter o filho, no caso de serem duas mulheres. Se vai ser adotado. Se se quer que seja um filho biológico ou não. No caso de dois homens, como é que isso vai ser feito? (Ana) 


\section{Condições e Desafios da Parentalidade ao Nível do Contexto Social}

Este tema remete para as condições e desafios da parentalidade que foram identificados pelos participantes ao nível do contexto social mais ampliado. Como nos dois temas anteriores, emergiram perceções genéricas, mas também específicas, associadas à orientação sexual, em particular as que reportaram para as atitudes da sociedade em relação à homossexualidade e homoparentalidade.

Começando pelas condições de âmbito geral, cinco participantes referiram-se à conciliação entre trabalho $e$ vida familiar como um desafio a ter em conta na decisão de ter filhos - "eu acho que a parentalidade, geralmente, pede mais tempo do que aquele que a pessoa tem quando trabalha a tempo inteiro" (Luís). Foi ainda referenciada $(n=5)$ a suficiência ou não dos apoios de natureza instrumental que, de um modo geral, a sociedade/rede formal disponibiliza para as famílias:

Coisas mais gerais mas que... me preocupam em relação à minha própria parentalidade um dia... Por exemplo, não haver... um apoio legal, uma segurança de residencia... as rendas são muito altas, não são reguladas pelo Estado e se tu vives numa casa e... não podes pagar a renda, o dono da casa... tem o direito de te pôr fora... Estando sozinho, não me preocupa nada, porque se acontecer eu vou para casa de um amigo ou da família, mas se tiveres uma família, já é um bocado diferente, não é? (Luís)

Relativamente às condições específicas, emergiram narrativas relacionadas com as atitudes sociais em relação à homossexualidade, por parte de todos os participantes, enquanto fenómeno transversal, incluindo as experiências no local de trabalho:

eu acho que pode haver um fator negativo... e eu, como homossexual, talvez já tenha sentido isso, muitas vezes, até na minha própria cabeça, por causa da sociedade... Eu acho que as coisas já estão a mudar muito... mas ainda há muitos preconceitos. E acho que não são preconceitos só das gerações mais velhas, há muitas pessoas da minha geração, de gerações mais novas que mantêm esses preconceitos. (Gil)

$O$ ambiente dos meus amigos não tem nada a ver com o ambiente trabalho... Eu imaginar-me a chegar ao trabalho e dizer que vou ter um filho com a minha namorada, era, de certeza, esperar que nos próximos anos as pessoas me vissem de forma diferente... e, decididamente, que eu me tornasse num boato e numa fonte de piadas. (Ana)

Complementarmente, ainda no que concerne às atitudes, registaram-se construções de sentido tendentes à compensação dos desafios que lhes estão associados por via da transformação da sociedade, ou pelo menos do meio imediato, complementando o que já foi mencionado relativamente ao coping, tanto ao nível pessoal (e.g., o investimento e a assunção de responsabilidades aumentados na parentalidade) como das relações próximas (e.g., o recurso ao apoio da comunidade gay). Neste âmbito foi referida a importância de investir na sensibilização social/ comunitária, por exemplo, por meio da escola e dos meios de comunicação (e.g., a televisão), "que são com quem as crianças passam mais horas ao longo do seu dia... [contribuindo para] moldar aquilo que elas acham normal ou não" (Nuno). Surgiu também, como possibilidade, a procura de locais mais inclusivos para constituir família - "eu para conseguir isso [ter filhos], não vai ser aqui [na minha terra]... Recuso-me a ter aqui a minha vida!" (Diana). Das narrativas evidenciou-se ainda a expectativa na mudança das atitudes, ancorada noutras mudanças sociais, enquanto oportunidade para o futuro:

Com os anos, eu penso que, as morais se alterem para achar isso normal, tal como se alteraram, num periodo que demorou, para o divórcio... Daqui a oito anos, grosso modo, já muita coisa vai ter mudado. Imensas coisas mudaram nos últimos cinco anos. Penso que algumas das dificuldades que eu neste momento não sei como lidar, saberei melhor [como lidar] ou já não existirão tão acentuadamente. (Nuno)

Intrinsecamente associado ao desafio que o heterossexismo representa neste domínio, surgiu a perceção de insuficiências do apoio da sociedade às famílias homoparentais, remetendo para apreensões de todos os participantes relativamente ao reconhecimento social/legal e às condições que lhes são ou não asseguradas pela rede formal, incluindo a atuação dos profissionais. Os impedimentos e constrangimentos legais no acesso à parentalidade (adoção e PMA) e no reconhecimento da família - que ainda vigoravam no momento da realização das entrevistas - foram claramente destacados a este nível. Paralelamente a esse destaque, a revisão da lei foi apontada por alguns dos participantes como uma oportunidade, "pelas condições materiais que dá... em tudo o que tenha a ver com legalidade no sistema educativo, no sistema de saúde... e, por outro lado, também pelo lado simbólico... [pelo] efeito protetor" (Luís). Apesar das transformações que, entretanto, se efetivaram a este nível, é fundamental referir também a perceção de que a mudança da lei não será suficiente, não obstante a sua importância - "a legislação... é o que nos rege enquanto sociedade, mas acho que não vai ser a mudança da legislação que vai fazer a mudança na sociedade" (João). Neste seguimento, foi exteriorizada insegurança relativamente à atuação da rede formal, nomeadamente: (a) na candidatura a adoção - "eu receio que sim. Eu acho que não se deve colocar [a questão da orientação sexual dos candidatos] mas, naturalmente, tem muito a ver com as pessoas que encontramos à frente a avaliar o processo" (Gil); (b) na relação com a escola - "ainda não sei como é que agiria se... essas críticas viessem da parte dos professores do meu filho" (Nuno); (c) e no contacto com os 
serviços de saúde - "apesar do acesso, em teoria, ser igual, a recetividade dos profissionais de saúde àquela família não vai ser igual"(Ana).

$\mathrm{Na}$ base destas inseguranças pareceu estar também a noção da representação heterossexista da parentalidade, onde "tudo o que não é... pai, mãe e filho, representa uma dificuldade acrescida [aumentada]" (Nuno). Possivelmente associada a esta perceção, cinco participantes referiram ainda a disponibilidade ou não de modelos (de homoparentalidade).
Essa (in)disponibilidade tanto foi enunciada de forma direta - "não tenho conhecimento de nenhum casal homossexual" (Gil) - como indiretamente, invocando outras configurações familiares diferentes da de casal heterossexual no momento de refletir sobre os desafios da homoparentalidade: "não penso que seja situação exclusiva das famílias homossexuais. Penso que uma familia, por exemplo, uma criança filha de uma mãe solteira possa ter tantas ou mais dificuldades" (Nuno).

\section{DISCUSSÃO}

Este estudo teve como objetivo identificar as perceções de jovens adultos portugueses sem filhos relativamente ao eventual projeto de homoparentalidade, num momento marcado pelo debate de alterações legislativas centradas sobre esta questão. O desejo de ter filhos foi referido pela maioria $(n=6)$ dos participantes, dado consistente com a diversidade de projetos identificada por Stacey (2006) e Aboim et al. (2012), também em estudos qualitativos, e surgiu associado a motivações positivas (Miller, 1994, 2011), como gostarem de crianças e quererem contribuir para o desenvolvimento de uma pessoa. Foi manifesto o adiamento dessa intenção, eventualmente, até estarem asseguradas as condições percebidas como necessárias. Algumas condições, assim como os desafios antecipados pelos participantes, são gerais. Outros foram especificamente associados à sua orientação sexual.

Começando pelos primeiros, na literatura sobre a parentalidade (e.g., Alarcão, 2006; Belsky, 1984, 2008; Hoghughi, 2004; Miller, 1994, 2011) também surgem evidenciadas a importância da estabilidade pessoal e económica, da estabilidade da relação com o/a companheiro/a, do apoio da rede informal e do apoio da rede formal às famílias. Mills et al. (2011) referiram a este propósito que as incertezas ao nível económico e as insuficiências das políticas de apoio às famílias são algumas das razões por que as pessoas têm adiado a parentalidade. Em estudos realizados com lésbicas e gays, a estabilidade laboral e económica (Aboim et al., 2012; Berkowitz, 2011; Berkowitz \& Marsiglio, 2007; Chabot \& Ames, 2004; Goldberg et al., 2012; Mezey como citado em Mezey, 2013; Rabun \& Oswald, 2009) e a estabilidade da relação de casal (Aboim et al., 2012; Berkowitz, 2011; Gianino, 2008; Goldberg et al., 2012; Rabun \& Oswald, 2009; Touroni \& Coyle, 2002) também se destacaram como fatores determinantes para a tomada de decisão de ter filhos. No nosso estudo, a valorização da estabilidade da relação de casal pareceu associar-se à idealização de um projeto parental partilhado.

Quanto às perceções que surgiram especificamente associadas à orientação sexual, mesmo considerando que esta - assim como o género dos pais/mães - não determina, per se, a competência parental nem a qualidade do desenvolvimento dos filhos, os participantes não se mostraram indiferentes às barreiras associadas ao heterossexismo que poderão ter que enfrentar (Brown et al., 2009; Goldberg, 2010; Herek, 2009). Assim, elencaram um conjunto de desafios e preocupações ao nível individual, relacional e do contexto social mais ampliado, interligados entre si e tendo como denominador comum as atitudes negativas da sociedade, cujo impacto consideraram ter que ser ponderado no que diz respeito às crianças. Esta apreensão relativamente às atitudes sociais foi identificada noutros estudos (Aboim et al., 2012; Berkowitz \& Marsiglio, 2007; Brown et al., 2009; Chabot \& Ames, 2004; Gianino, 2008; Rabun \& Oswald, 2009; Touroni \& Coyle, 2002).

Desenvolvendo esta análise, no nível individual foi referida como condição para a intenção de ter filhos a vivência do coming out, fundamental para a autoaceitação e bem-estar (Meyer, 2003) e perspetivada como uma tarefa em aberto, que exige uma negociação permanente com os outros e com a sociedade em geral (American Psychological Association, 2012; Herek, 2009). Tendo em conta o desejo de partilha das responsabilidades parentais, a existência de discrepâncias no casal relativamente à abertura com o exterior emergiu como um desafio adicional a ter em conta nessa vivência (Frost et al., 2017).

Os desafios na relação com os outros pareceram refletirse de modo particular na insegurança percebida pelos participantes relativamente ao apoio da família e amigos para o projeto de homoparentalidade. Estas apreensões já tinham surgido nos estudos de Baiocco e Laghi (2013), Berkowitz e Marsiglio (2007), Brown et al. (2009), Chabot e Ames (2004) e Touroni e Coyle (2002). No nosso estudo, essa insegurança associou-se à perceção de não valorização desse projeto por parte dos outros, a qual parece ter sido construída pelos participantes a partir das mensagens de desconforto e inautenticidade recebidas do exterior (e.g., o pai que disse "não vou ter netos a sério").

Essa perceção de insegurança também se estendeu ao contexto social mais ampliado, não apenas no que se refere às atitudes da sociedade em relação à homoparentalidade, ou aos dispositivos de apoio a estas famílias, como os legais (percebidos como importantes mas não suficientes), mas também no contacto com serviços e profissionais 
intervenientes nas questões da infância e família, à semelhança do que concluíram Berkowitz e Marsiglio (2007), Brown et al. (2009) e Gianino (2008). Enquadrando uma leitura ecológica (Bronfenbrenner, 1977; Goldberg, 2010), os participantes não só ponderaram os desafios já experimentados nos contextos mais próximos, mas anteciparam aqueles com que se poderão deparar na altura de concretizar a decisão de ter filhos; além disso, não se focaram apenas na transição para a parentalidade, mas anteveem o exercício da parentalidade ao longo do desenvolvimento dos filhos (e.g., na escola). É de realçar que não se mostraram dissuadidos pelos eventuais constrangimentos legais.

Ainda como desafio foi antecipada a falta de modelos para a futura família, que também foi identificada por Brown et al. (2009) e Touroni e Coyle (2002), cujas participantes referiram sentir as suas famílias como pioneiras a este nível. Tendo em conta a distância temporal que separa o nosso estudo da pesquisa de Touroni e Coyle (2002), esta perceção dos participantes pode ter-se devido à pouca visibilidade da homoparentalidade em Portugal, atendendo ao seu reconhecimento ainda pouco expressivo no plano social (Costa et al., 2013; Ramos et al., 2016) e em consolidação no plano jurídico.

Mas as narrativas dos participantes não ficam circunscritas a apreensões, revelando igualmente expectativas de mudanças na sociedade e a consequente transformação das oportunidades que daí possam advir (Elder, 1998; Gato et al., 2017; Goldberg, 2010), o que é convergente com as pesquisas de Rabun e Oswald (2009) e Touroni e Coyle (2002). Além disso, perante o reconhecimento dos desafios anteriormente elencados, elaboraram uma reflexão sobre as condições e recursos a considerar para a tomada de decisão de ter filhos.

Ao nível pessoal, e em consonância com outros estudos (Berkowitz \& Marsiglio, 2007; Bos et al., 2003; Chabot \& Ames, 2004; Gianino, 2008), os participantes anteciparam a necessidade de uma reflexão e um investimento aumentados relativamente ao projeto de parentalidade, não apenas por razões relacionadas com o acesso em si, mas também porque qualquer decisão terá que implicar a salvaguarda da criança. Este compromisso veio reforçar a existência de uma ponderação refletida e crítica do projeto de parentalidade e da intenção de terem filhos, que parece contrastar com a reserva existente em torno destas famílias em Portugal (e.g.,
Costa et al., 2013; Ramos et al., 2016). Essa ponderação estendeu-se à antecipação da necessidade de serem assumidas responsabilidades parentais aumentadas ao longo do ciclo vital da família. Os participantes anteveem as suas responsabilidades parentais como acrescidas porque, para além das funções de apoio e proteção, educação e integração sociocultural dos filhos (Alarcão, 2006), deverão incluir a preparação (de todos) para lidar com o estigma, vivido/ esperado, de forma adaptativa (Herek, 2009). Mais uma vez, foi manifesta a perceção de que o estatuto de minoria sexual obriga a negociações permanentes com o exterior, por exemplo, com a escola dos filhos. Esta ponderação em torno das estratégias de coping também foi identificada nos estudos de Brown et al., (2009), Chabot e Ames (2004) e Rabun e Oswald (2009).

O compromisso de investimento e a responsabilização aumentados também se refletiram ao nível relacional, nomeadamente na negociação que foi percebida como necessária dentro do casal. A procura ativa de informação e a salvaguarda da criança foram estendidas ao casal, que terá que refletir e chegar a consensos em aspetos que, para além de serem instrumentais no acesso à parentalidade (e.g., decisão de quem vai fazer inseminação), poderão ter implicações na forma como vai ser construído o sentido de si como pai/mãe e a relação com a criança (e.g., ter ou não um laço biológico com ela). Essa negociação pareceu ainda ligar-se ao desejo de partilha de responsabilidades revelada por alguns participantes, em função das características e interesses individuais, dado que parece ser consistente com a conceção de "parentalidade sem género" (degendering parenting) referida por Rabun e Oswald (2009, p. 282).

Complementando a reflexão em torno de estratégias de coping, o apoio da comunidade gay foi valorizado por alguns dos participantes em consonância com o que foi verificado noutras pesquisas (Berkowitz \& Marsiglio, 2007; Chabot \& Ames, 2004; Costa \& Bidell, 2017; Gianino, 2008; Goldberg et al., 2012), assim como a ponderação da procura de contextos comunitários mais inclusivos para constituir família, também reportada por Rabun e Oswald (2009). Esta reflexão em torno da procura e criação de redes de apoio para a futura família foi particularmente notória no caso da participante que residia num contexto mais pequeno, percebido como não aceitante, podendo ainda configurar uma alternativa à não valorização do projeto de parentalidade por parte da família e restante rede de proximidade.

\section{CONSIDERAÇÕES FINAIS}

No sentido de identificar as perceções de jovens adultos portugueses sem filhos relativamente ao eventual projeto de homoparentalidade foram realizadas entrevistas a lésbicas, gays e bissexuais. As narrativas dos participantes traduziram uma motivação associada à ponderação refletida, crítica, responsável e contextualizada do (eventual) projeto de homoparentalidade. Mesmo considerando que a orientação sexual não determina a competência parental nem o desenvolvimento das crianças, per se, não foram descuradas as possíveis influências do heterossexismo. Assim, para além de se referirem a um conjunto de condições que, no geral, consideraram fundamentais para a tomada de decisão de ter 
filhos, como a estabilidade pessoal, económica, da relação afetiva e o apoio da rede informal e formal, os participantes também equacionaram os desafios associados ao estatuto de minoria sexual. Esses desafios foram perspetivados relativamente a várias questões: (a) ao eventual impacto das atitudes negativas da sociedade nos (futuros) filhos; (b) nas vivências do coming out, individual/do casal, enquanto tarefa permanente nas trocas com exterior; (c) na insegurança quanto ao apoio por parte da família e restante rede informal, associada à perceção da não valorização/ dificuldade de aceitação do eventual projeto parental; (d) nos constrangimentos esperados nos contactos com a rede formal (e.g., os serviços de adoção, a escola dos filhos); e (e) na (in) disponibilidade de modelos para a família. Todavia, também animados pela expectativa de mudanças na sociedade e das oportunidades que daí possam resultar, os participantes refletiram sobre os recursos que poderão ser mobilizados para a gestão desses desafios. Assim, ao nível pessoal, identificaram a necessidade de um investimento aumentado e consciente da salvaguarda das crianças, preocupação que se estendeu para a reflexão sobre as (eventuais) futuras responsabilidades parentais. A perspetiva de partilhar o projeto parental com um/a companheiro/a levou à extensão dessa intencionalidade para o casal, por meio da negociação de aspetos ligados às alternativas de acesso à parentalidade, e eventualmente, também com a abertura ao exterior. Foi ainda equacionada a procura/criação de redes (alternativas) de apoio para a futura família.

O facto dos resultados reportarem perceções prospetivas sobre os desafios esperados e os recursos que são antecipados para os enfrentar constitui um contributo para a reflexão particularmente pertinente neste momento, nomeadamente em Portugal - sobre condições que permitam otimizar as experiências de lésbicas e de gays que pretendam ter filhos, uma vez que as alterações na Lei não são suficientes. Além disso, podem constituir a base de mudanças a nível social, dos profissionais e dos próprios indivíduos no sentido de facilitar essa tomada de decisão. Assim, os resultados do presente estudo, para além de contribuírem para a compreensão das especificidades das vivências de pessoas lésbicas e gays que aspiram a concretizar o projeto de parentalidade, também apelam à necessidade de investir na formação e sensibilização dos profissionais com responsabilidades na área da família. Essa formação deverá enquadrar a compreensão das necessidades específicas das minorias sexuais, quer a nível individual, quer relacional e social/comunitário, nomeadamente: (a) o desenvolvimento de estratégias para gerir os desafios do heterossexismo, discriminação e homofobia internalizada, de acordo com uma abordagem afirmativa e promotora do bem-estar (e.g., APA, 2012); (b) o conhecimento/disponibilização de informação sobre as formas de acesso à parentalidade, como a adoção e as técnicas de PMA, suas caraterísticas e condições e a sensibilização para a importância de incluir outras famílias homoparentais na rede informal de apoio; e (c) a responsabilização profissional na transformação dos contextos onde se movem estas famílias.

Este estudo tem algumas limitações a considerar, associadas essencialmente às características sociodemográficas dos participantes, designadamente a exclusividade de habilitações académicas de nível superior e o facto de se terem autoproposto para participar no estudo. Estas limitações têm sido reportadas na literatura da área (cf. Goldberg et al., 2014). Não obstante, ainda que os resultados não possam ser generalizados para outras situações além das que dizem respeito a este estudo, espera-se que as conclusões possam ser úteis em contextos semelhantes e que possam ser encontradas conexões com outras experiências pessoais e profissionais, assim como com outros estudos (Smith \& Osborn, 2008; Yardley, 2008). Como propostas para trabalhos futuros, seria importante analisar o(s) processo(s) de transição para a parentalidade de lésbicas e gays, no contexto português, mais concretamente, conhecer os aspetos decisivos ou pontos de virada (Goldberg, 2010) na tomada de decisão, os desafios (efetivamente) encontrados, e a forma como são integrados, ou não, o investimento e a noção de responsabilidade aumentada.

\section{REFERÊNCIAS}

Aboim, S., Costa, C., \& Gomes, N. (2012). Famílias LGBT e políticas públicas. In Observatório das Famílias e Políticas de Família (Org.), Seminário Políticas Públicas e Novas Parentalidades. http://www.observatoriofamilias.ics. ul.pt/images/OFAPseminario2012/aboim\%20_costa_\%20 gomes_\%20familias $\% 20 \operatorname{lgbt} \% 20 \mathrm{e} \% 20$ politicas $\% 20$ publicas. pdf

Alarcão, M. (2006). (Des)Equilibrios familiares: Uma visão sistémica (3a ed.). Quarteto.

American Psychological Association. (2005). Lesbian and gay parenting. Author.

American Psychological Association. (2012). Guidelines for psychological practice with lesbian, gay, and bisexual clients. American Psychologist, 67(1), 10-42. https://doi.org/10.1037/ a0024659
Baiocco, R., \& Laghi, F. (2013). Sexual orientation and the desires and intentions to become parents. Journal of Family Studies, 19(1), 90-98. https://doi.org/10.5172/jfs.2013.19.1.90

Belsky, J. (1984). The determinants of parenting: A process model. Child Development, 55(1), 83-96. https://doi. org/10.2307/1129836

Belsky, J. (2008). Social-contextual determinants of parenting. In R. Tremblay, M. Boivin, \& R. Peters (Eds.), Encyclopedia on Early Childhood Development ( $2^{\mathrm{a}}$ ed. pp. 1-6). Centre of Excellence for Early Childhood Development and Strategic Knowledge Cluster on Early Child Development.

Berkowitz, D. (2011). Maternal instincts, biological clocks, and soccer moms: Gay men's parenting and family narratives. Symbolic Interaction, 34(4), 514-535. https://doi.org/10.1525/ si.2011.34.4.514 
Berkowitz, D., \& Marsiglio, W. (2007). Gay men: Negotiating procreative, father, and family identities. Journal of Marriage and Family, 69(2), 366-381. https://doi.org/10.1111/j.17413737.2007.00371.x

Bos, H., van Balen, F., \& van den Boom, D. (2003). Planned lesbian families: Their desire and motivation to have a child. Human Reproduction, 18(10), 2216-2224. https://doi.org/10.1093/ humrep/deg 427

Bronfenbrenner, U. (1977). Toward an experimental ecology of human development. American Psychologist, 32, 513-531. https://doi.org/10.1037/0003-066X.32.7.513

Brown, S., Smalling, S., Groza, V., \& Ryan, S. (2009). The experiences of gay men and lesbians in becoming and being adoptive parents. Adoption Quarterly, 12(3), 229-246. https:// doi.org/10.1080/10926750903313294

Chabot, J., \& Ames, B. (2004). “It wasn't 'let's get pregnant and go do it"': Decision making in lesbian couples planning motherhood via donor insemination. Family Relations, 53(4), 348-356. https://doi.org/10.1111/j.0197-6664.2004.00041.x

Costa, P. A., \& Bidell, M. (2017). Modern families: Parenting desire, intention, and experience among Portuguese lesbian, gay, and bisexuals individuals. Journal of Family Issues, 38(4), 500-521. https://doi.org/10.1177/0192513X16683985

Costa, P. A., Caldeira, S., Fernandes, I., Rita, C., Pereira, H., \& Leal, I. (2013). Atitudes da população portuguesa em relação à homoparentalidade. Psicologia: Reflexão e Crítica, 26(4), 790-798. https://doi.org/10.1590/S0102-79722013000400020

Elder, G. (1998). The Life Course as developmental theory. Child Development, 69(1), 1-12.

Finlay, L. (2014). Engaging Phenomenological Analysis. Qualitative Research in Psychology, 11(2), 121-141. https://doi.org/10.10 80/14780887.2013.807899

Frost, D. M., LeBlanc, A. J., de Vries, B., Alston-Stepnitz, E., Stephenson, R., \& Woodyatt, C. (2017). Couple-level minority stress: An examination of same-sex couples' unique experiences. Journal of Health and Social Behavior, 58(4), 455-472. https://doi.org/10.1177/0022146517736754

Gato, J. (2016). Beyond comparison: New trends in research with families with GLB members in Europe. Journal of GLBT Family Studies, 12(1), 1-4. https://doi.org/10.1080/155042 8X.2016.1127095

Gato, J., Santos, S., \& Fontaine, A. M. (2017). To have or not to have children? That is the question. Factors influencing parental decisions among lesbian and gay men. Sexuality Research and Social Policy, 14(3), 310-323. https://doi.org/10.1007/ s13178-016-0268-3

Gianino, M. (2008). Adaptation and transformation: The transition to adoptive parenthood for gay male couples. Journal of GLBT Family Studies, 4(2), 205-243. https://doi. org/10.1080/15504280802096872

Goldberg, A. E. (2010). Lesbian and gay parents and their children: Research on the family life cycle. American Psychological Association.

Goldberg, A. E., Downing, J., \& Moyer, A. (2012). Why parenthood, and why now? Gay men's motivations for pursuing parenthood. Family Relations, 61(1), 157-174. https://doi.org/10.1111/ j.1741-3729.2011.00687.x

Goldberg, A. E., Gartrell, N., \& Gates, G. (2014). Research report on $L G B$-parent families. The Williams Institute, UCLA School of Law. http://williamsinstitute.law.ucla.edu/wp-content/uploads/ lgb-parent-families-july-2014.pdf

Herek, G. (2009). Sexual stigma and sexual prejudice in the United States: A conceptual framework. In D. A. Hope (Ed.), Nebraska Symposium on Motivation: Vol. 54. Contemporary perspectives on lesbian, gay, and bisexual identities (pp. 65-111). Springer Science + Business Media.
Hoghughi, M. (2004). Parenting-an introduction. In M. Hoghughi \& N. Long (Eds.), Handbook of parenting. Theory and research for practice (pp. 1-18). Sage.

Lei n. 2, de 29 de fevereiro de 2016. (2016). Elimina as discriminações no acesso à adoção, apadrinhamento civil e demais relações jurídicas familiares.

Lei $n$. 9, de 31 de maio de 2010. (2010). Permite o casamento civil entre pessoas do mesmo sexo.

Lei $n$. 17, de 20 de junho de 2016. (2016). Alarga o âmbito dos beneficiários das técnicas de procriação medicamente assistida, procedendo à segunda alteração à Lei n. ${ }^{\circ} 32 / 2006$, de 26 de julho.

Lei n. 32, de 26 de julho de 2006. (2006). Procriação medicamente assistida.

Lincoln, Y., Lynham, S., \& Guba, E. (2011). Paradigmatic controversies, contradictions, and emerging confluences, revisited. In N. Denzin \& Y. Lincoln (Eds.), The SAGE Handbook of Qualitative Research (4 ${ }^{\mathrm{a}} \mathrm{ed}$, pp. 97-128). Sage.

Meyer, I. (2003). Prejudice, social stress, and mental health in lesbian, gay, and bisexual populations: Conceptual issues and research evidence. Psychological Bulletin, 129(5), 674-697. https://doi.org/10.1037/0033-2909.129.5.674

Mezey, N. J. (2013). How lesbians and gay men decide to become parents or remain childfree. In A. E. Goldberg \& K. R. Allen (Eds.), LGBT-parent families. innovations in research and implications for practice (pp. 59-70). Springer Services + Business Media.

Miller, W. (1994). Childbearing motivations, desires and intentions: A theoretical framework. Genetic, Social, and General Psychology Monographs, 120(2), 223-258.

Miller, W. (2011). Differences between fertility desires and intentions: Implications for theory, research and policy. Vienna Yearbook of Population Research, 9, 75-98. http://www.jstor. org/stable/41342806

Mills, M., Rindfuss, R. , McDonald, P., \& te Velde, E. (2011). Why do people postpone parenthood? Reasons and social policy incentives. Human Reproduction Update, 17(6), 848-860. https://doi.org/10.1093/humupd/dmr026

Ordem dos Psicólogos Portugueses. (2013). Relatório de evidência científica psicológica sobre relações familiares e desenvolvimento infantil nas famílias homoparentais. Author.

Papalia, D. E., Olds, S. W., \& Feldman, R. D. (2006). Desenvolvimento humano ( $8^{\mathrm{a}} \mathrm{ed}$.). Artmed.

QSR International. (2008). NVivo (Version 8) [Computer Software]. QSR International Pty.

Rabun, C., \& Oswald, R. F. (2009). Upholding and expanding the normal family: Future fatherhood through the eyes of gay male emerging adults. Fathering, 7(3), 269-285. https://doi. org/10.3149/fth.0703.269

Ramos, V., Atalaia, S., \& Cunha, V. (2016). Vida familiar e papéis de género: Atitudes dos Portugueses em 2014 (Research brief 2016). Instituto de Ciências Sociais da Universidade de Lisboa. http://www.observatoriofamilias.ics.ul.pt/

Riskind, R., \& Patterson, C. (2010). Parenting intentions and desires among childless lesbian, gay, and heterosexual individuals. Journal of Family Psychology, 24(1), 78-81. https://doi. org/10.1037/a0017941

Smith, J. A. (2011). Evaluating the contribution of interpretative phenomenological analysis. Health Psychology Review, 5(1), 9-27. https://doi.org/10.1080/17437199.2010.510659

Smith, J. A., \& Osborn, M. (2008). Interpretative Phenomenological Analysis. In J. A. Smith (Ed.), Qualitative Psychology. A practical guide to research methods ( $2^{\mathrm{a}}$ ed., pp. 53-80). Sage.

Stacey, J. (2006). Gay parenthood and the decline of paternity as we knew it. Sexualities, 9(1), 27-55. https://doi. org/10.1177/1363460706060687 
Touroni, E., \& Coyle, A. (2002). Decision-making in planned lesbian parenting: An Interpretative Phenomenological Analysis. Journal of Community \& Applied Social Psychology, 12(3), 194-209. https://doi.org/10.1002/casp.672

Xavier, P., Alberto, I., \& Mendes, F. (2017). Same-sex parenting: Identification of social representations in a sample of Portuguese professionals. Journal of Homosexuality, 66, 274296. https://doi.org/10.1080/00918369.2017.1400314
Yardley, L. (2008). Demonstrating validity in qualitative psychology. In J. A. Smith (Ed.), Qualitative Psychology. A practical guide to research methods (2a ed., pp. 235-251). Sage.

Yin, R. (2011). Qualitative research from start to finish. The Guilford Press. 